\title{
Abundance and distribution of nocturnal fishes over a coral reef during the night
}

\author{
Roi Holzman ${ }^{1,2,3, *}$, Moty Ohavia ${ }^{1}$, Royi Vaknin ${ }^{1,2}$, Amatzia Genin ${ }^{1,2}$ \\ ${ }^{1}$ The Inter-University Institute for Marine Sciences of Eilat, PO Box 469, 88103 Eilat, Israel \\ ${ }^{2}$ Department of Evolution, Systematics and Ecology, The Hebrew University of Jerusalem, Israel \\ ${ }^{3}$ Present address: Section of Evolution and Ecology, University of California, One Shields Ave., Davis, California 95616, USA
}

\begin{abstract}
Coral reefs are characterized by high abundance of fishes, which often have marked effects on the recruitment, nutrition, and reproduction of coral reef inhabitants. Despite the fact that fish are active over the coral reef at night, very little is known of their whereabouts or about their contribution to those processes. In the present study, the abundance and distribution of nocturnal fishes were studied over a coral reef near Eilat, Red Sea. Sampling was conducted between the surface and $15 \mathrm{~m}$ depth, using a stereoscopic camera system that surveyed $3.5 \mathrm{~m}^{3}$ of water every $2 \mathrm{~min}$. The density of zooplanktivorous species ranged from 0.7 to 7.4 fish $100 \mathrm{~m}^{-3}$, accounting for $>60 \%$ of the total nocturnal fishes recorded. Fish abundance decreased with increasing distance from shore and with increasing height above bottom. Larger fish foraged at greater heights above bottom. While the appearance of zooplanktivorous fishes after sunset and their disappearance before sunrise corresponded to that of demersal zooplankton, inter-night variation in fish abundance was unrelated to variation in zooplankton abundance. Furthermore, neither current speed nor moon illumination accounted for inter-night variations in fish abundance, perhaps indicating some degree of site fidelity. The abundance of zooplanktivorous fishes was $\sim 30$-fold lower during the night than day. However, since nocturnal fishes feed on larger zooplankters, the biomass of zooplankton preyed upon by nocturnal fishes was similar to that of diurnal species. This study suggests that the paradigm of negligible predation by nocturnal fishes should be reconsidered.
\end{abstract}

KEY WORDS: Coral reef fishes - Nocturnal zooplanktivory $\cdot$ Nocturnal ascent $\cdot$ Photogrammetry · Fish community

Resale or republication not permitted without written consent of the publisher

\section{INTRODUCTION}

Several decades of research on the ecology of coral reef fishes yielded much information on the distribution and feeding ecology of diurnal fishes (e.g. Fricke 1980, Hamner et al. 1988, Kingsford \& MacDiarmid 1988, Forrester 1991, Hobson 1991, Brokovich 1999, Rilov \& Benayahu 2000). However, only a handful of reports on nocturnal fishes are available, and most of this information is either qualitative (Hobson \& Chess 1978, Gladfelter 1979) or it is focused on stomach content and dietary partitioning among species (Hobson \& Chess 1978, Gladfelter 1979) or on the distribution of these fish during daytime (Brokovich 1999, Rilov \& Benayahu 2000, Khalaf \& Kochzius 2002). Further- more, standard methodological approaches, such as the use of flashlights and line transects, limit the relevance of the findings to specific habitats (e.g. lagoons [Marnane \& Bellwood 2002] and the benthic boundary layer [Annese \& Kingsford 2005]), while data on the temporal patterns of nocturnal fishes during the night are largely restricted to dusk and dawn (Fishelson et al. 1971, Hobson 1972, McFarland et al. 1999, Yahel et al. 2005a). Therefore, a quantitative study of the spatial and temporal distributions of nocturnal fish is necessary in order to understand their role in the ecology of coral reefs.

The distribution and behavior of nocturnal animals can greatly differ from that of related diurnal species. An extreme example is the diel migration of zooplank- 
ton, which distinguishes its distribution from that of 'diurnal', non-migrating zooplankton (e.g. Bollens \& Frost 1989). In coral reefs, the distribution of diurnal zooplanktivorous fishes is apparently related to their swimming ability, with large, mobile fish found seaward and higher above bottom than small fish (Hobson \& Chess 1978, Hamner et al. 1988, Hobson 1991). Since prey availability for those fishes is greater further away from the reef (Hamner et al. 1988, Holzman et al. 2005), the paucity of small fish from preferred, preyreplete zones is believed to be determined by the risk of predation (Fricke 1980, Hixon 1991). However, little is known on the distribution of nocturnal zooplanktivorous fishes across the reef, or the role of predation in structuring that distribution. If predation is lower for nocturnal fish, food may play a major role in determining their distribution. If this is the case, their distribution is expected to follow that of demersal zooplankton (a major component of the diet of coral-reef nocturnal fishes; Hobson \& Chess 1978, Gladfelter 1979, Marnane \& Bellwood 2002), which emerges from the bottom after sunset and ascends to several meters above bottom (Alldredge \& King 1985).

Recent advances in digital photography have made available a wide range of instruments designed to sample fish, micronekton, and zooplankton (Harvey \& Shortis 1995, Wiebe \& Benfield 2003, Harvey et al. 2004, Benoit-Bird \& Au 2006). The use of cameras can help to overcome some of the known biases and artifacts of visual transects (Sale 1997), and uniquely allows the accumulation of time-series data.

The objective of the present study was to quantify the abundance of nocturnal fish along a cross-shore $(0$ to $90 \mathrm{~m}$ from shore) and a depth gradient (0 to $15 \mathrm{~m}$ ) over a coral reef. Further, the study aims to describe the temporal patterns of fish emergence, abundance, and retreat throughout the night. Lastly, we aimed to examine the possible relationships between fish distribution at a selected depth and potential correlates, including light intensity, flow speed, and zooplankton abundance and distribution.

\section{MATERIALS AND METHODS}

Study site. The fieldwork was carried out at the coral reef off the H. Steinitz Marine Biology Laboratory in Eilat, Israel $\left(29^{\circ} 30^{\prime} \mathrm{N}, 34^{\circ} 56^{\prime} \mathrm{E}\right)$. The local fish community was described by Brokovich (1999), Rilov \& Benayahu (2000), and Khalaf \& Kochzius (2002). Briefly, the guild of diurnal zooplanktivorous fish is dominated by site-attached species such as the reef anthias Pseudanthias squamipinnis, several damselfishes (including Neopomacentrus miryae and Dascyllus spp.), and more mobile species such as Caesio
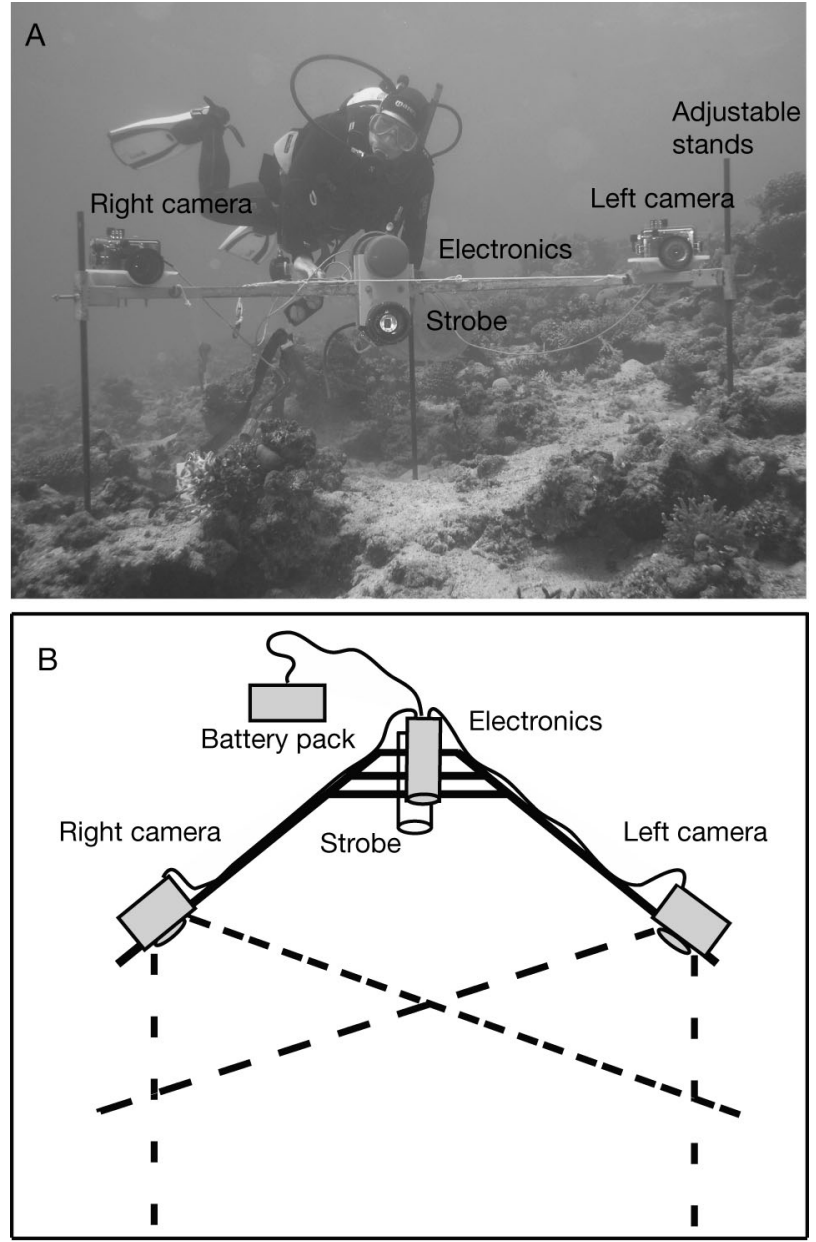

Fig. 1. (A) The fish camera recorder (FCR) deployed in the reef at $5 \mathrm{~m}$ depth. The battery pack is obscured by a coral head. (B) Schematic drawing of the FCR. Dashed lines demarcate the field of view of each camera

spp. and Abudefduf spp. The most abundant nocturnal zooplanktivorous fishes include several Apogonidae (Apogon cyanosoma, Apogon aureus, Apogon annularis, Cheilodipterus quinquelineatus), Myripristis spp., and Pempheris vanicolensis (Rilov \& Benayahu 2000). The benthic community at this low-relief reef (Fig. 1A) was described by Benayahu \& Loya (1977). The reef is dominated by hermatypic corals, and hydrozoans, soft corals, mollusks, sponges, and tunicates are also abundant. The coastal currents are weak, with an average speed of $\sim 10 \mathrm{~cm} \mathrm{~s}^{-1}$ and a strong semidiurnal periodicity of current reversal during the warm period (May to September). The zooplankton community in the oligotrophic water around the reef is dominated by small $(<0.5 \mathrm{~mm})$ taxa of which copepods comprise $>50 \%$ (Farstey et al. 2002, Sommer et al. 2002). Zooplankton abundance above the reef nearly doubles at night (1000 to 2000 ind. $\mathrm{m}^{-3}$ ), relative 
to daytime values, mostly due to an increase in large demersal zooplankters (>200 $\mu \mathrm{m}$ ) (Yahel et al. 2005b). The distribution of small zooplankton over the reef is characterized by a spatial gradient, its density in the benthic boundary layer (up to $\sim 2 \mathrm{~m}$ above bottom [mab]) is about $50 \%$ of that in the water above (Holzman et al. 2005, Yahel et al. 2005b).

Photographic system. The abundance of nocturnal fishes over the coral reef was quantified using a stereo photographic system, capable of recording fish within a volume of $3.5 \mathrm{~m}^{3}$. The system, termed the fish camera recorder (hereafter FCR), consisted of 2 digital cameras (Coolpix 5400, Nikon) in underwater housings (SN 6194, Ikelite) mounted on the arms of a V-shaped steel frame, with a strobe (150 $\mathrm{W} \mathrm{s}^{-1}$; PhotoSea 1500sx) located at the frame's base (Fig. 1). The 2 cameras were oriented at $45^{\circ}$ to the main axis of the FCR, so that most of their fields of view overlapped (Fig. 1B). The arms of the FCR frame were $\sim 1.5 \mathrm{~m}$ in length and perpendicular to one another. The underwater camera housings were attached to the rig using custom-made cradles, molded to fit the bottom of the housings, so that detaching and reattaching the cameras did not change their position and orientation. The $24 \mathrm{~V}$ power pack consisted of 2, serially connected $12 \mathrm{~V}$ standard motorcycle batteries (sealed, non-spillable lead-acid 6.6 Amp h ${ }^{-1}$, Yuasa Battery) contained in a custom-made fiberglass housing. The cameras and the strobe were synchronized to simultaneously record a pair of images every 2 min, thereby minimizing artifacts related to attraction or avoidance of fish and zooplankton to the light source (Jaffe et al. 1998, Mueller et al. 2006).

Spatial distribution of fishes over the reef. FCR deployments were made between October 2004 and February 2005 at above-bottom depths of 1, 2, 5, and $15 \mathrm{~m}$, to assess the spatial distribution and abundances of nocturnal fishes along cross-shore (0 to $90 \mathrm{~m}$ from shore) and depth (surface to bottom) transects (hereafter 'spatial observations'; see Table 1 and Fig. 2 for information on deployment locations and naming). At the near-bottom stations the FCR was fixed at the designated height using a 3-leg frame made from galvanized steel pipes (Fig. 1A). At the mid-water and nearsurface stations, a taut mooring line anchored with a $25 \mathrm{~kg}$ weight and suspended with a $18 \mathrm{l}$ subsurface float was used to suspend the FCR at the designated depths. The FCR was deployed $>1 \mathrm{~h}$ before sunset and retrieved $\sim 1 \mathrm{~h}$ after sunrise. Deployments were replicated 6 times per station (total of 42 nights) at different locations on the reef, haphazardly selected along the target bathymetric contours. Since the FCR quantified the abundance of fish at the same position during the entire night, our sampling unit was a whole night and the dependent variable was the average density of fish during each night (see below).
Fishes recorded with the FCR were sorted to the finest taxonomic level possible, usually genus or species. Fishes belonging to Lethrinidae and Lutjanidae could not be resolved one from another and were grouped.

Effects of moonlight, current speed, and zooplankton abundance. The abundance and distribution of fish over the coral reef at our study site were characterized by strong spatio-temporal variations (see 'Results'). To test for possible effects of moon illumination, current speed, and zooplankton density on fish abundance, an extensive, 22 night long set of observations (hereafter 'temporal observations') was recorded during August and September 2005 at Point 12B, located at the bottom depth of $12.5 \mathrm{~m}$ (with the FCR positioned $0.8 \mathrm{mab}$ ). At that depth, the variation in moonlight between fullmoon and moonless nights is expected to have an impact on the feeding rates of nocturnal fish (Holzman \& Genin 2003, R. Holzman unpubl. data). Currents were measured simultaneously with FCR records in 20 of these deployments using an upward looking acoustic doppler current profiler (ADCP, $600 \mathrm{kHz}$ Workhorse, RDI Instruments) deployed near ( 2 $\mathrm{m})$ the FCR. For logistic reasons, ADCP records were not available on 2 of the nights. The ADCP's echo-intensity records are correlated with the total volume, total cross section, and wet weight of the zooplankton (Flagg \& Smith 1989; based on concurrent ADCP records and MOCNESS hauls) and can therefore be used as a surrogate for zooplankton density (Flagg \& Smith 1989, Yahel et al. 2005a). Following Flagg \& Smith (1989), the backscattering values reported by the ADCP were used as a proxy for zooplankton biomass, with no correction for transmission loss and radial spreading. Therefore, the use of this proxy was limited to comparisons of the same data bins between different nights (at the same location using the same ADCP setup). Note that the above echo-intensity data cannot be used to quantitatively compare zooplankton biomass between different distances from the transducer.

The upward looking ADCP was programmed to record current speed and echo intensity in the range of 0.75 to $6.75 \mathrm{mab}$ (in $0.5 \mathrm{~m}$ bins). Thus, the 'noisy' near-transducer and near-surface ranges $(10 \%$ of the range) were omitted from the measured range according to the manufacturer's instruction manual (RDI Instruments). To improve data visualization and interpretation, the values of acoustic backscatter within the experimental nights were normalized and standardized as: normalized echo intensity $=\left(E_{i}-\right.$ $\bar{E}) / \mathrm{SD}(E)$, where $E_{i}$ is the $i$ th echo intensity value, $\bar{E}$ is the average echo intensity from all the experimental nights, and $\mathrm{SD}(E)$ is the respective standard deviation. The FCR was deployed $>1 \mathrm{~h}$ before sunset and retrieved $\sim 1 \mathrm{~h}$ after sunrise. Synchronized half-hourly 


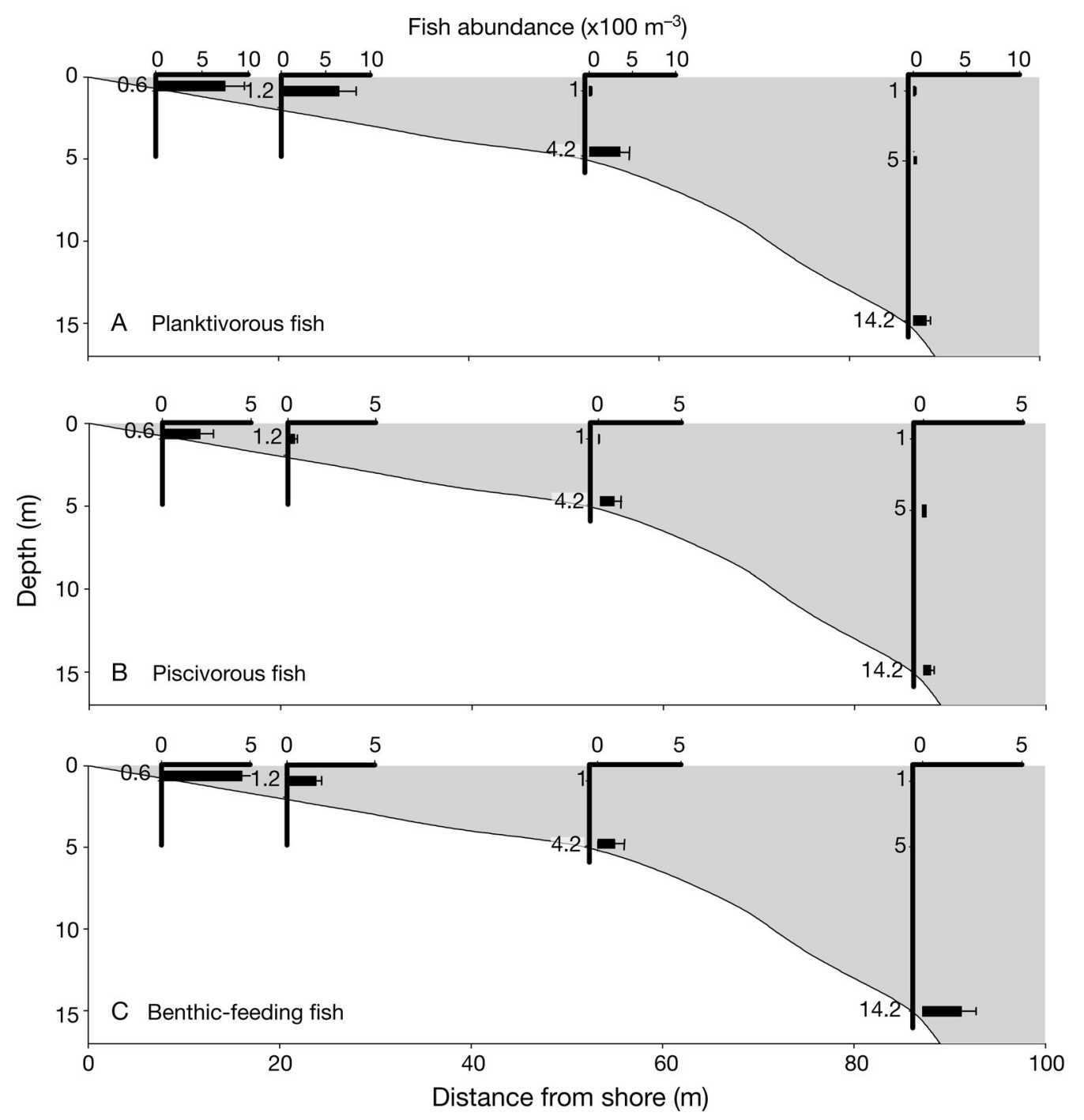

Fig. 2. Spatial patterns: abundance of planktivorous (A), piscivorous (B), and benthic-feeding fishes (C) over the coral reef of Eilat overlaid on bottom topography at the study site. Continuous line demarcates the water column (gray) and bottom (white) areas. Tics in the inner graphs indicate the locations of the camera system and the center of the sampled volume; note the different scales on the $x$-axes for the densities of the different fish guilds (A-C). Error bars $=\mathrm{SE}, \mathrm{n}=42$ nights, 6 nights per sampling point

means of both the FCR (fish densities) and ADCP records were used for the analyses.

Sampled volume and photogrammetry. The volume sampled by the FCR was measured in a large circular pool, $4 \mathrm{~m}$ in diameter and $3 \mathrm{~m}$ deep, with the FCR fixed at $1.5 \mathrm{~m}$ depth near the pool's wall. The volume of the pool was divided into $10 \mathrm{~cm}^{3}$ 'voxels' (3-dimensional analog of pixels), using a 3-dimensional grid. The center of each voxel was defined by moving a taut mooring line with distinct vertical marks at $10 \mathrm{~cm}$ intervals across a $10 \times 10 \mathrm{~cm}$ grid marked on the pool's floor. A photograph of the mooring was taken at each location by the 2 cameras, and the coordinates of each voxel were recorded using image analysis software
(Imagepro for Windows Ver. 4.5, Media Cybernetics), resulting in a coordinate set of $X_{\text {(left) }}, Y_{\text {(left), }} X_{\text {(right) }}, Y_{\text {(right) }}$ (hereafter 2-dimensional coordinates) for each voxel center. The sampled volume was defined as the cumulative volume of all the voxels appearing in both cameras, up to a distance of $3.5 \mathrm{~m}$ from the strobe, forming a $3.5 \mathrm{~m}^{3}$ polygon, $200 \times 140 \times 210 \mathrm{~cm}$ in maximal height, width, and length, respectively. The length of the sampled volume, defined by the pool diameter, was conservative with regard to visibility as in the field, where fish were frequently observed farther away. We used this shorter range, and made fine adjustment of the FCR position, in order to minimize the obstruction of fish by topographic features. 
At the near-surface and -bottom stations, the sampled volume had to be truncated because the water and bottom surfaces, respectively, appeared in the images. The size of the sampled volume at those stations $\left(1.5\right.$ to $\left.3.4 \mathrm{~m}^{3}\right)$ was determined photogrammetrically for each deployment. At Stns $1 \mathrm{~B}$ and $2 \mathrm{~B}$ the height of the sampled volume was measured every hour, to account for tidal changes.

Only objects appearing in the 2 cameras were considered valid 'targets'. For each target, we recorded the 2-D coordinates from each of the left and right cameras $\left(X_{\text {(left) }}, Y_{\text {(left) }}, X_{\text {(right) }}, Y_{\text {(right) }}\right)$ using ImagePro (Ver. 4.5). These coordinates were used to resolve the 3-D location of each target relative to the camera (see Fig. 1 in Benoit-Bird \& Au 2006). The translation to 3-D was based on a maximum-likelihood algorithm using the target's coordinates and the calibration matrix by finding the voxel for which the RMS distance to the target's 2-D coordinates was minimal. A tank test with haphazardly positioned targets $(n=30)$ indicated that all position assignments were correct. The precision was $\pm 5 \mathrm{~cm}$ in each dimension. For the fish recorded with the FCR (body size in the range of 5 to $35 \mathrm{~cm}$ ), the spatial resolution had an error that never exceeded the fish's body size, appropriate for measuring the fish's abundance and vertical distribution.

Temporal and statistical analysis. The time of sunrise and sunset, moonrise and moonset, moon phase, and the number of moon minutes in each night were obtained from the Wise Observatory Astronomical Calendar, Tel Aviv University, Israel (http://wise-obs.tau. ac.il/ eran/Wise/wise_calen.html). In order to assess the spatial distribution of nocturnal fishes over the reef, we used 1-way ANOVA with station (7 levels) as the independent factor and the mean density of zooplanktivorous fishes within each sampling night as the dependent variable. We chose to use a 1-way ANOVA rather than a 2-way design with missing cells in the shallow stations (depth $\times$ distance from shore) since the FCR surveyed the entire water column in the shallow stations, thereby leaving no gaps in the water column. A similar analysis was made for piscivorous fishes. Since no benthic-feeding fishes were observed at $>2$ mab (see 'Results'), the effect of station on their density was assessed using only the 4 bottom stations.

In order to assess the effects of environmental parameters on the fish's temporal distribution, we used multiple regression with mean current speed, number of moon minutes, and echo intensity as independent variables and the mean density of nocturnal fishes within each sampling night at the $12 \mathrm{~m}$ station as the dependent variable. ANCOVA was used to test the effect of moon illumination (number of moon minutes, continuous predictor) and taxa (categorical predictor) on the foraging height of all fishes observed.
Possible correspondence between temporal variations in the abundance of fish and zooplankton was examined using linear regression, with fish abundance and acoustical backscatter as the dependent and independent variables, respectively. Data for this analysis consisted of half-hourly means of fish densities and backscatter, averaged across sampling nights. In all cases, ANOVA, ANCOVA, and $t$-tests were performed only after verifying homogeneity of variance using Cochran's statistics. Atherinomorus spp. was excluded from the analysis of the effect of moon phase on foraging height, since this taxon was observed to be surface bound. Data on the density of predators contained many zeroes; therefore, Spearman rank order was used to test for correlation between the density of planktivorous and piscivorous fish. All the aforementioned statistical tests were performed using STATISTICA Ver. 6.0 for Windows (StatSoft). The differences in species composition and relative abundances across sampling stations were tested using 1-way analysis of similarity (Clarke \& Warwick 1994) based on the Bray-Curtis similarity index. To assess the effect of environmental variables on community pattern, we used the BioEnv procedure (PRIMER Ver. 5.0), which selects environmental variables best explaining community pattern by maximizing a rank correlation between their respective similarity matrices (Clarke \& Warwick 1994). The latter tests were performed using PRIMER Ver. 5.0 (Plymouth Marine Laboratory).

\section{RESULTS}

\section{Spatial patterns}

A total of 2277 fish were observed with the FCR during 64 nights (Tables 1 \& 2). The density of zooplanktivorous fishes, which accounted for $\sim 60 \%$ of the fishes observed, varied significantly with sampling station (ANOVA, $F_{6,35}=6.31, \mathrm{p}<0.001$; Fig. $2 \mathrm{~A}$, Table 1 ). The highest density of zooplanktivorous fish was observed near the bottom at the shallowest stations (Stns 1B and $2 \mathrm{~B} ;$ average $\pm \mathrm{SE}: 0.074 \pm 0.028$ and $0.066 \pm 0.019$ fish $\mathrm{m}^{-3}$, respectively). The abundance values of nocturnal fishes at Stns 5S (0.0019 \pm 0.0009$)$, 15S (0.0016 \pm $0.0005)$, and $15 \mathrm{M}\left(0.0007 \pm 0.0004 \mathrm{fish}^{-3}\right)$ were 1 to 2 orders of magnitude lower than those at Stns $1 \mathrm{~B}$ and 2B (Tukey honestly significant difference, $\mathrm{p}<0.05$ for all cases).

The abundances of piscivorous fishes were also significantly different between different sampling locations (ANOVA, $F_{6,35}=5.14, p<0.001$ ). The density of piscivorous fishes was positively correlated to that of zooplanktivores (Spearman rank order, $r=0.65, n=42$, $\mathrm{p}<0.01$; Fig. 2B). Nocturnal benthic-feeding fish ap- 
peared only near the bottom (Fig. 2C), with a non-significant effect of sampling location (ANOVA, $F_{3,20}=$ 2.56, $\mathrm{p}=0.083$, 'bottom' locations only).

The taxonomic composition of the fish community differed significantly between sampling locations (ANOSIM, R $=0.5, \mathrm{p}<0.05$ ). At the shallow stations (1 and $2 \mathrm{~m}$ ), small zooplanktivores accounted for $>64 \%$ of the planktivores ( $41 \%$ of total fish), compared with $<30 \%$ of planktivores (19\% of total fish) at the deeper stations (5 and $15 \mathrm{~m}$ ). Together, Myripristis spp. and Pempheris vanicolensis accounted for 51 and $24 \%$ of the total fish density in deep and shallow stations, respectively.

A calculation of the integrated fish abundance throughout the water column (Table 1) indicates that the abundances of planktivorous, benthic-feeding, and

Table 1. Spatial patterns: sampling locations and variation in the integrated abundance of nocturnal fishes at our study site. Camera position indicates the height at which the camera was positioned above the bottom or below the surface. Abundance values were integrated from the bottom to the surface using the mean density at each site at each depth $(n=6)$ for all the deployments made at $1,2,5$, and $15 \mathrm{~m}$ depths (mean $\pm \mathrm{SE}$; total of 42 nights). Data are presented in abundance per area to facilitate comparison with other studies. Zoo: zoo planktivorous fish; Pisc: piscivorous fish; Bent: benthic-feeding fish

\begin{tabular}{|lccccc|}
\hline $\begin{array}{l}\text { Sampling } \\
\text { depth } \\
(\mathrm{m})\end{array}$ & Stn & Camera position & \multicolumn{3}{c|}{$\begin{array}{c}\text { Integrated abundance } \\
\text { (fish } 100 \mathrm{~m}^{-2} \text { ) }\end{array}$} \\
\hline 1 & & & Zoo & Pisc & Bent \\
2 & 1B & 0.4 m above bottom & $5.2(1.2)$ & $1.1(0.27)$ & $3.11(0.9)$ \\
5 & 2B & 0.8 m above bottom & $4.7(1.4)$ & $0.33(0.1)$ & $1.3(0.3)$ \\
& 5B & 0.8 m above bottom & $4.6(0.3)$ & $0.6(0.13)$ & $2.3(0.55)$ \\
15 & 5S & 1 m below surface & & & \\
& 15B & 0.8 m above bottom & $1.9(0.05)$ & $0.35(0.1)$ & $1.1(0.5)$ \\
& 15M & 5 m below surface & & & \\
& 15S & 1 m below surface & & & \\
\hline
\end{tabular}

piscivorous fishes were 2.5 to 3 times greater at the shallow stations $(1,2$, and $5 \mathrm{~m})$ than at $15 \mathrm{~m}$ depth.

\section{Temporal patterns}

Planktivorous fish were first to emerge after sunset $(22 \pm 10$ min after sunset, $\mathrm{n}=22$ nights; Fig. 3). The time of disappearance in the pre-dawn hours varied greatly between different deployments, with a mean $( \pm \mathrm{SE})$ of $1.43 \pm 1.26 \mathrm{~h}$ before sunrise (Fig. 3). Benthicfeeding and piscivorous fishes retreated to their daytime shelters $1.16 \pm 1.066 \mathrm{~h}$ before sunrise $(\mathrm{n}=22)$.

During the night at the $12 \mathrm{~m}$ station, the density of nocturnal fish was correlated with normalized echointensities (linear regression, $\mathrm{R}^{2}=0.44, F_{1,22}=18.8, \mathrm{p}<$ 0.01; Fig. 3). At that depth, there was no significant effect of current speed, number of moon minutes, or echo intensity on the density of the zooplanktivores (multiple regression, adj. $\mathrm{R}^{2}<0.1, F_{3,16}=1.68, \mathrm{p}>0.2$; Fig. $4 \mathrm{~A}$ ) or on the density of benthic-feeding and piscivorous fishes (multiple regression, adj. $\mathrm{R}^{2}<0.1, \mathrm{p}>0.1$ for both; Fig. 4B,C). Similarly, independent variations in average backscatter intensity, the number of moon minutes, or current speed could not explain the variations observed in average fish density between sampling nights (Spearman correlation, $\mathrm{r}=0.01$, -0.04 , and -0.21 , respectively, $\mathrm{df}=19$, p > 0.05 for all 3 variables; Fig. 4D). Within sampling nights, the density of planktivorous fish was not signifi-

Table 2. Spatial patterns: summary data for the abundance of the common fish species observed at the coral reef of Eilat, Israel. Data are averages for all sampling stations for all sampling nights of 'spatial pattern' deployments $(1,2,5,15 \mathrm{~m}$ depths; B, M, S stations; total of 42 nights). 'Number of nights' in which a fish from a given species was observed at least once is given. 'In stations' indicates sampling locations in which fishes of a given species were found; underlining indicates the stations at which the average density of the species was highest. About $1 \%$ of the fish observed with the fish camera recorder could not be identified

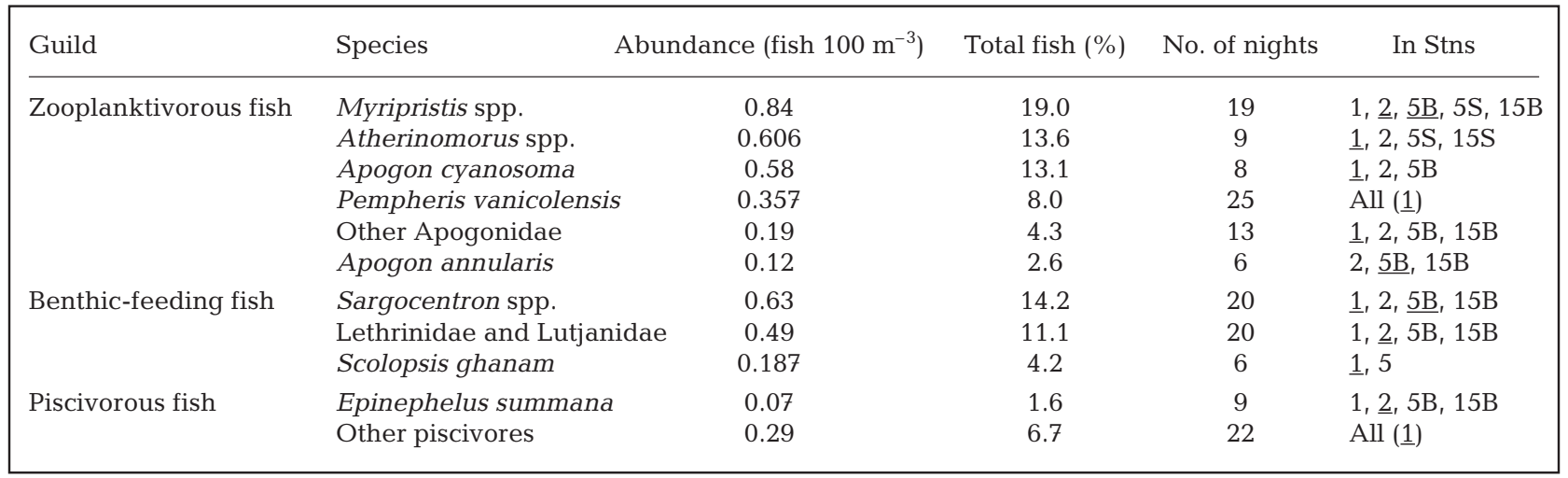


Time before sunrise $(\mathrm{h})$

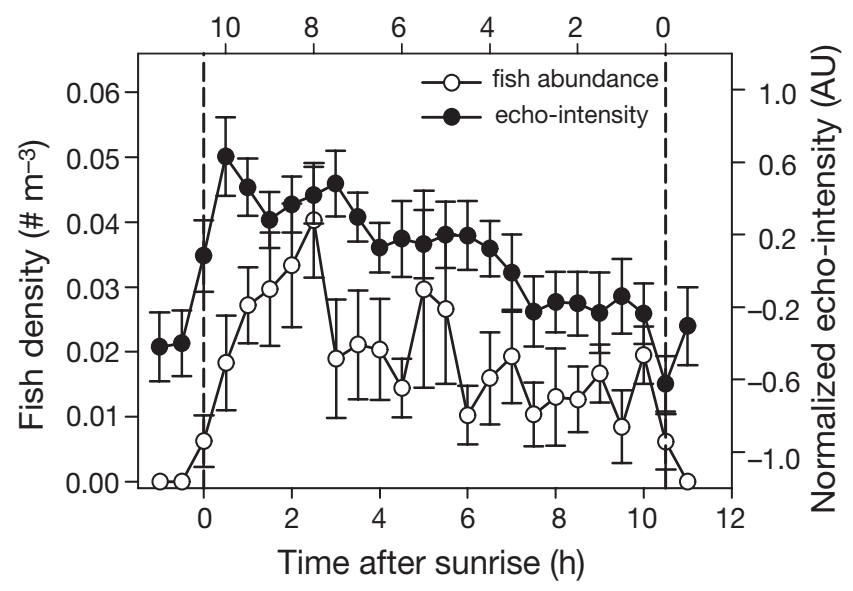

Fig. 3. Temporal patterns: within-night variations in the abundance of zooplanktivorous fish and echo intensity (zooplankton relative abundance) above the coral reef measured at 0.75 to $2.25 \mathrm{~m}$ above bottom at $12 \mathrm{~m}$ depth $(\mathrm{n}=20$ nights). Sunrise was $10.5 \mathrm{~h}$ after sunset. Error bars = SE cantly different before or after moonrise (paired $t$-test, $\mathrm{df}=19, t=-1.55, \mathrm{p}>0.13)$. Variation in environmental variables (number of moon minutes, current speed, and echo-intensity) could not explain the observed variations in the community pattern of planktivorous fishes (BioEnv R > 0.2 for all combinations).

\section{Foraging heights}

The vertical height above bottom of different taxa differed significantly (ANOVA, $F_{11,779}=98.3$, p $<0.001$; Fig. 5). Within the guild of planktivores, larger species were found higher above the bottom (Spearman correlation between standard length and the average foraging height of each species, $\mathrm{r}=0.76, \mathrm{n}=7, \mathrm{p}<$ 0.05; maximal length taken from Randall 1983). Myripristis spp. and Pempheris vanicolensis, the largest planktivorous fishes observed, were found highest above the bottom, at $77 \pm 6$ and $125 \pm 23 \mathrm{~cm}$ above bottom, respectively. Apogon cyanosoma, the

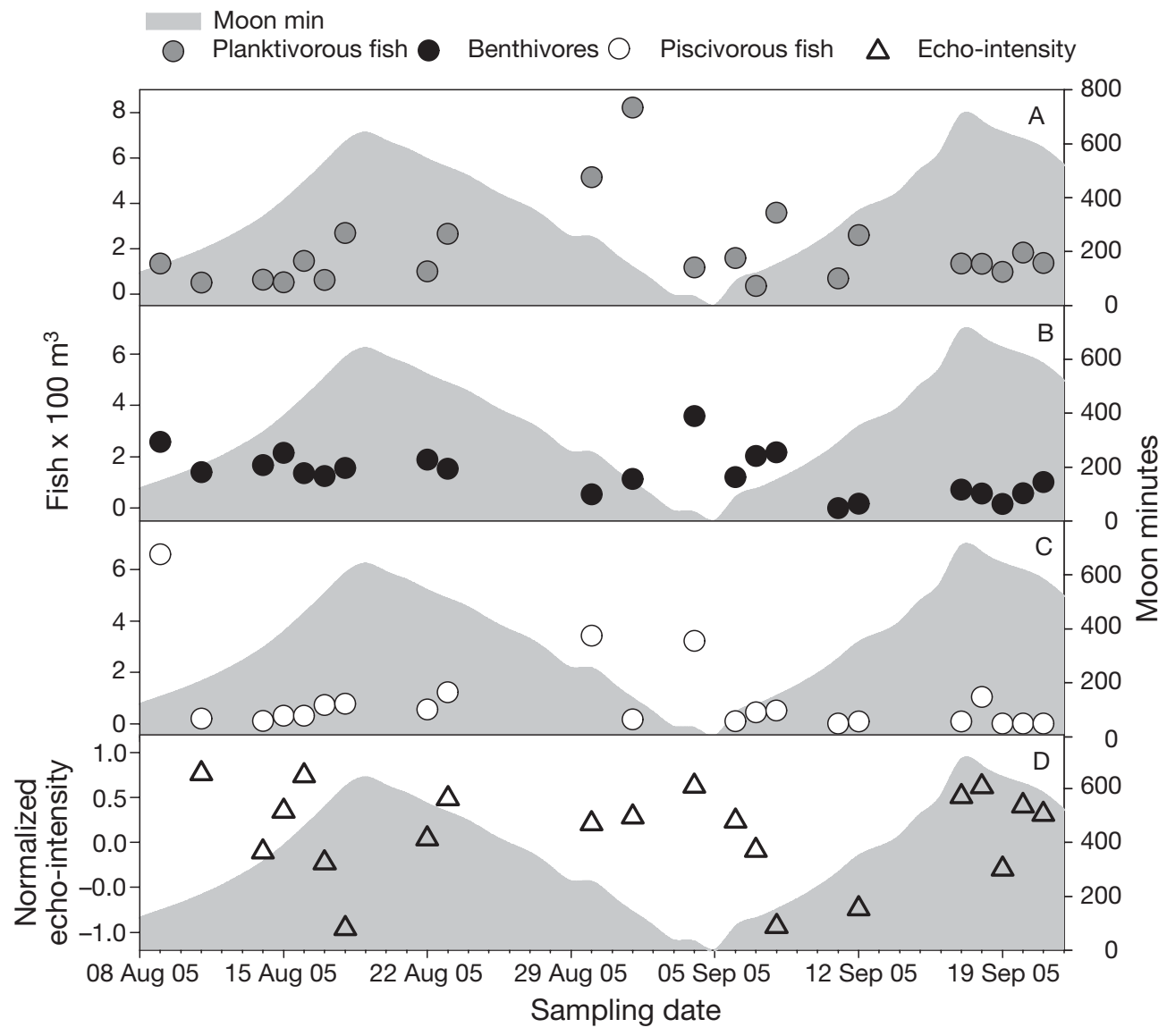

Fig. 4. Temporal patterns: between-night variations in the abundance of zooplanktivorous (A), benthic-feeding (B), and piscivorous fishes (C), and in echo-intensity (D) at $12 \mathrm{~m}$ depth in the coral reef of Eilat, overlaid on the number of moon minutes in each deployment night (gray background). Note, however, that shorter moon illumination corresponds to partial moon and, hence lower light intensity during those nights. $\mathrm{n}=22$ nights (20 for D) 


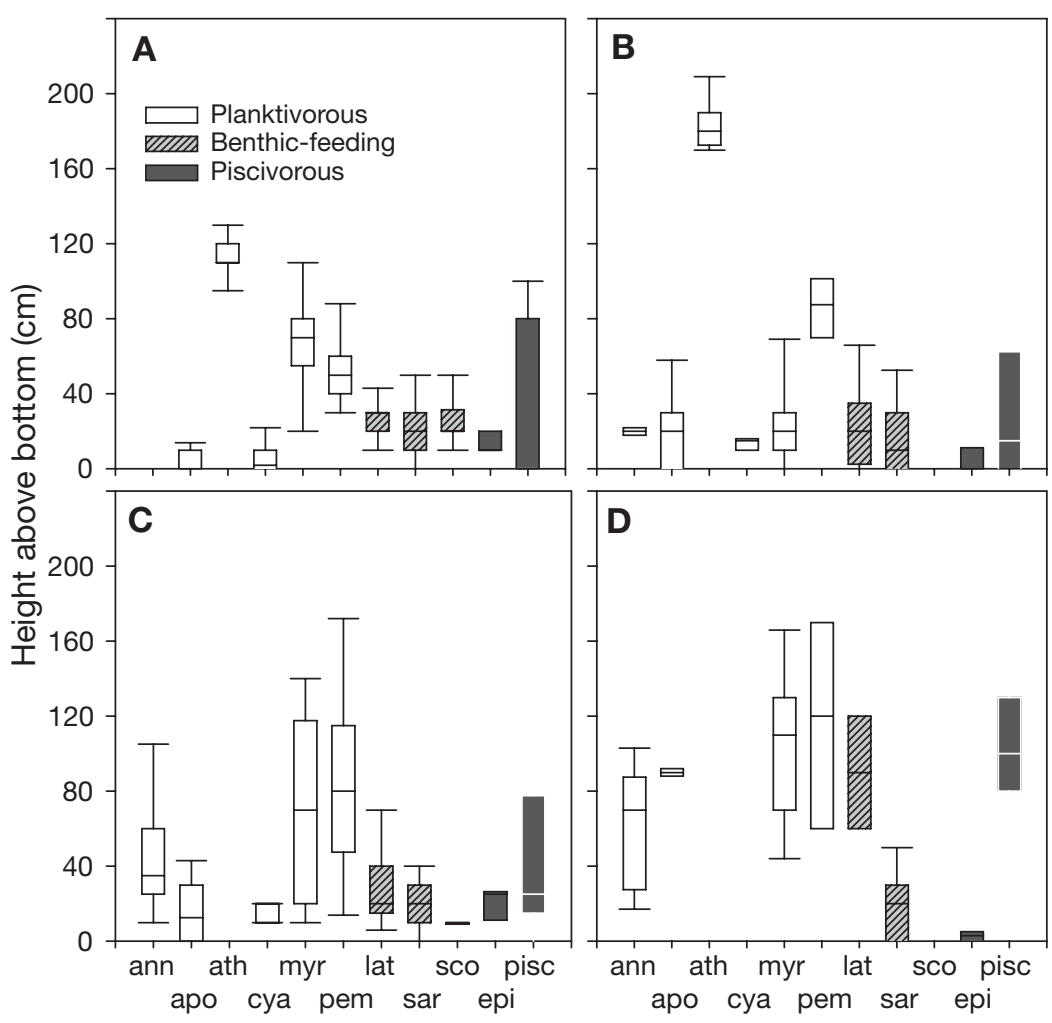

Fig. 5. Spatial patterns: foraging height for 11 fish taxa observed at bottom stations 1B (A), 2B (B), 5B (C), and 15B (D). Upper and lower portions of each box indicate the 75 th and 25 th percentiles of foraging heights, vertical line within each box indicates the median, and error bars denote the 10th and 90th percentiles. ann: Apogon annularis; apo: other Apogonidae; ath: Atherinomorus spp.; cya: Apogon cyanosoma; myr: Myripristis spp.; pem: Pempheris vanicolensis; lat: Lethrinidae and Lutjanidae; sar: Sargocentron spp.; sco: Scolopsis ghanam; epi: Epinephelus summana; pisc: piscivorous fish

for all cases; Bonferroni correction applied). Similarly, no moon effect on echo intensities in the bottom layer ( 0.75 to $2.25 \mathrm{mab})$ was observed ( $t$-test, $\mathrm{df}=38, t=0.88, \mathrm{p}>0.38$ ) or on the vertical gradient of echo intensity, calculated as the ratio between echo intensity at 0.75 to 1.25 and at 1.75 to 2.25 mab for all available records (38 nights; $t$-test, $\mathrm{df}=37, t=1.82, \mathrm{p}>$ 0.05).

\section{DISCUSSION}

Quantitative estimates of the abundance of nocturnal fishes are usually made using belt transects or sampling quadrates (Marnane \& Bellwood 2002, Annese \& Kingsford 2005) that require the use of continuous artificial light. In addition to possible artifacts due to attraction and avoidance of nocturnal fish (and their food) by light, belt transects may be biased due to a narrow field of view that is delimited by the artificial light source and the consequent increased probability of fish passing undetected through the transect area (Sale 1997). The key advantages of the FCR were the provision of accurate time series of high-resolution images. The sampled volume's proximal edge was $\sim 1.5 \mathrm{~m}$ away from the

smallest planktivorous fish, was found at an average height of $9 \pm 1 \mathrm{~cm}$ above bottom. Atherinomorus spp. were observed only near the water surface above all bottom depths, at an average depth of $15 \pm 10 \mathrm{~cm}$ below the surface.

Some of the fish taxa were foraging higher above the bottom during full moon nights, as indicated by the significant interaction term between taxa and number of moon minutes (ANCOVA, $F_{8,809}=4.08, \mathrm{p}<0.001$ ). The height above bottom observed for Myripristis spp., Pempheris vanicolensis, Epinephelus summana, and 'other piscivores' was positively correlated with the number of moon minutes (Spearman correlation, $\mathrm{p}<$ 0.005; Bonferroni correction applied), indicating that these fish foraged higher during better-illuminated nights. For example, Myripristis spp. and P. vanicolensis were foraging 0.5 and $0.25 \mathrm{~m}$ higher above bottom, respectively, during full moon nights than during nomoon. No significant effect of moon phase on foraging height was observed for other planktivorous or benthic-feeding species (Spearman correlation, p > 0.005
FCR, minimizing the effect of its presence on the fish. The powerful strobe we used could have temporarily 'blinded' the fish, but we used a short (4 ms) pulse and a long interval between successive records (2 min) to minimize this effect.

The density of nocturnal planktivores recorded in our study was about 30 times lower than that of diurnal planktivores at the same site (diurnal fish quantified using $50 \times 2 \mathrm{~m}$ belt transects; E. Brokovich unpubl. data, R. Holzman unpubl. data). These densities are similar to those reported by Annese \& Kingsford (2005) for nocturnal Pempherididae in temperate reefs in Australia $\left(\sim 10\right.$ fish $\left.100 \mathrm{~m}^{-2}\right)$. However, zooplanktivorous fish at their study site were more abundant in the depth range from 10 to $14 \mathrm{~m}$, while in Eilat their density was higher in shallow (1 to $2 \mathrm{~m}$ ) waters. The densities reported for both reef habitats are higher than those reported for 2 pempherid fishes collected by otter trawling in a non-reef habitat in the coastal waters of southwestern Australia ( 0.01 to 1 fish $100 \mathrm{~m}^{-2}$; Platell \& Potter 1999). 
Using the FCR, we tested the effects of 3 possible factors on the spatial distribution of nocturnal planktivorous fishes above the coral reef at night: the density of piscivorous fishes, light intensity (moon phase), and prey density. The positive correlation in the abundances of piscivorous and planktivorous fishes might indicate that predation risk affected the tendency of smaller fish to remain near the bottom. Reduced feeding rates at lower light intensities in deeper waters (Holzman \& Genin 2003) might explain the lower abundance of fish at greater depths. For Apogon annularis, under equal prey density, the potential feeding rate under the light intensity at $2 \mathrm{~m}$ is $95 \%$ of that at $1 \mathrm{~m}$, but only $\sim 80$ and $35 \%$ at 5 and $15 \mathrm{~m}$ depths, respectively (Holzman \& Genin 2003). However, the relative rarity of zooplanktivorous fishes near the surface indicates that attraction to stronger light was not a major factor determining their foraging location (Fig. 2). Apparently, fish avoided foraging away from the bottom (mid-water and near-surface water) due to the lack of either topographic shelters or navigational markers, or another unknown reason. The weak correlations between environmental factors and the abundance of nocturnal fishes ('temporal patterns') might indicate some degree of site fidelity (Marnane 2000) through niche separation, territoriality, or another mechanism.

An abrupt increase in the density of zooplankton was observed exactly at sunset $(0 \pm 8 \mathrm{~min}$ after sunset), peaking $30 \mathrm{~min}$ after sunset (Yahel et al. 2005a; Fig. 3 in the present study). In accordance, the nocturnal fish emerged, on average, 22 min after sunset (Fig. 3). Similarly, the fish disappeared from the water column $86 \pm$ 76 min before sunrise (Fig. 3), in accordance with the timing of the descent of nocturnal zooplankton $(82 \pm$ 10 min before sunrise at our study site; see Yahel et al. 2005a). This temporal overlap persisted through the night, as indicated by the correlation between the halfhourly means of nocturnal zooplanktivorous fish and backscatter intensity at $12 \mathrm{~m}$ depth.

The ADCP backscatter was used as a proxy for the density of zooplankton. However, the fish themselves could have contributed to the backscatter values, rendering trivial the correlation between the fish and ADCP backscatter intensity (Fig. 3). To indirectly test this possibility, we compared the ADCP backscatter values at 0.75 mab (where fish are abundant) to those at $5.25 \mathrm{mab}$ (where the density of fish was very low). In a previous study (Holzman et al. 2005), we showed that the densities of zooplankton at 0.25 to 1.25 mab and at 5 mab were strongly correlated. Thus, if the backscatter intensity is determined mostly by fish, no correlation of that intensity between 0.75 and 5.25 mab should be expected. The fact that the correlation in zooplankton densities was high (Spearman correlation, $\mathrm{r}=0.88$, $\mathrm{p}<0.001)$ and similar to that $(\mathrm{r}=0.82)$ observed for zooplankton counts (Holzman et al. 2005) suggests that the backscattering value was mostly determined by zooplankton density.

The pattern observed in the backscattering values could have been affected by suspended sediments. However, the quantity of suspended sediments at our site exhibits a diel cycle only in the $1 \mathrm{mab}$, with a sharp decrease during the night, but no detectable changes higher (>1 m) in the water column (Yahel et al. 2002, $2005 b)$. This cycle is due to reduced resuspension by burrowing fish, which are active only during the day (Yahel et al. 2005b). Therefore, it is highly unlikely that the increase in echo intensity at nightfall (Figs. $3 \& 5$; Yahel et al. 2002, 2005a) is due to suspended sediments.

Our findings can be used to estimate the overall zooplanktivory rate by the entire guild of nocturnal zooplanktivorous fish at our study site. To do so, we use the in situ feeding rates found for the nocturnal fish Apogon annularis by Holzman \& Genin (2003) as the representative feeding rate for all planktivorous species. Since this species is smaller than most of the zooplanktivorous fishes observed in this study, our estimate is likely to be conservative, as feeding rate increases with body size (Jobling 1993). Multiplying the average feeding rate of $25 \mu \mathrm{g} \mathrm{C} \mathrm{min}{ }^{-1}$ fish $^{-1}$ (observed in the field, under natural zooplankton densities; Holzman \& Genin 2003) with the interpolated density of zooplanktivorous fish between the shoreline and $15 \mathrm{~m}$ depth (3.7 fish $\mathrm{m}^{-1}$; Table 1), the total zooplankton predation is approximately $6.5 \mathrm{mg} \mathrm{C} \mathrm{m}^{-2} \mathrm{~d}^{-1}$ (considering $11 \mathrm{~h}$ of feeding each night, on average) or $2.4 \mathrm{~g} \mathrm{C} \mathrm{m}^{-2} \mathrm{yr}^{-1}$. The integrated abundance of zooplanktivorous fish on the reef was calculated based on lengths of 15,20,35, and $20 \mathrm{~m}$ for 1, 2, 5, and $15 \mathrm{~m}$ depths, respectively (Fig. 2, Table 1). These estimates are similar to those calculated by Hamner et al. (1988) for diurnal zooplanktivores at Davis Reef, Great Barrier Reef (2.8 $\left.\mathrm{g} \mathrm{C} \mathrm{m}^{-2} \mathrm{yr}^{-1}\right)$. This high predation rate can substantially contribute to import of carbon and nutrients from the open water to the reef community (Erez 1990). However, unlike diurnal fish, which feed primarily on neritic and pelagic holoplankton, a large portion (40 to $70 \%$; Marnane \& Bellwood 2002, Holzman \& Genin 2003) of the zooplankton consumed by nocturnal fish is of reef origin (mero- and demersal plankton). This high predation by nocturnal zooplanktivores can be the reason for the gradual decline in zooplankton abundance during the night (Fig. 3). However, behavioral causes, such as a gradual descent of satiated zooplankton to the bottom late at night (Pearre 2003), cannot be ruled out.

It is generally accepted that zooplankton detection by visual predators is much reduced at night (e.g. Gli- 
wicz 1986, O'Brien 1987, Bollens \& Frost 1989, Giske et al. 1994) and that the weak predation pressure in darkness is the most likely explanation for other major trends in benthic ecosystems, including the nocturnal release of gametes and larvae (Harrison \& Wallace 1990, Morgan \& Christy 1995, Hovel \& Morgan 1997), the occurrence of larval recruitment during the night (e.g. Acosta et al. 1997, Acosta \& Butler 1999), and the nocturnal ascent of many demersal (bottom-associated) zooplankton species into the water column (Yahel et al. 2005a). However, the claim that zooplankton is protected from visual predation at night is hard to reconcile with the high abundance of nocturnal, visual zooplanktivorous fishes over the coral reef, as reported in this study. The role of nocturnal fishes in the trophic dynamics of shallow benthic communities can be far more important than has so far been assumed.

Acknowledgements. We are indebted to S. Rickel, M. Kiflawi, U. Motro, D. Wiehs, G. Katzir, and D. Collar for discussions and reviews, to H. Skibinski, T. Kats, Y. Belmaker, G. Winters, R. Kent, A. Bar-Gill, O. Polack, and O. Ben-Shaprut for their assistance with the field work, to N. Segev for help with the image analyses, and T. Holzman for the continuous support. We are grateful to the Interuniversity Institute of Eilat for logistic support. R.H. thanks the Rothberg family and the Rieger Foundation for their financial support. The study was supported by the Israel Science Foundation (Grant Number 484/03).

\section{LITERATURE CITED}

Acosta CA, Butler MJ (1999) Adaptive strategies that reduce predation on Caribbean spiny lobster postlarvae during onshore transport. Limnol Oceanogr 44:494-501

Acosta CA, Matthews TR, Butler Iv MJ (1997) Temporal patterns and transport processes in recruitment of spiny lobster (Panulirus argus) postlarvae to south Florida. Mar Biol 129:79-85

Alldredge AL, King JM (1985) The distance demersal zooplankton migrate above the benthos: implications for predation. Mar Biol 84:253-260

Annese DM, Kingsford MJ (2005) Distribution, movements and diet of nocturnal fishes on temperate reefs. Environ Biol Fish 72:161-174

Benayahu Y, Loya Y (1977) Space partitioning by stony corals, soft corals and benthic algae on the coral reefs of the northern Gulf of Eilat (Red Sea). Helgol Wiss Meeresunters 30:362-382

Benoit-Bird KJ, Au WWL (2006) Extreme diel horizontal migrations by a tropical nearshore resident micronekton community. Mar Ecol Prog Ser 319:1-14

Bollens SM, Frost BW (1989) Zooplanktivorous fish and variable diel vertical migration in the marine planktonic copepod Calanus pacificus. Limnol Oceanogr 34:1072-1083

Brokovich E (1999) The community structure and biodiversity of reef fishes at the northern Gulf of Aqaba (Red Sea) with relation to their habitat. MSc thesis, Tel Aviv University (in Hebrew)

Clarke KR, Warwick RM (1994) Changes in marine communi- ties: an approach to statistical analysis and interpretation. Natural Environment Research Council, Plymouth

Erez J (1990) On the importance of food sources in coral-reef ecosystems. In: Dubinsky Z (ed) Ecosystems of the world, Vol 25. Coral reefs. Elsevier, Amsterdam, p 411-418

Farstey B, Lazar B, Genin A (2002) Expansion and homogeneity of the vertical distribution of zooplankton in a very deep mixed layer. Mar Ecol Prog Ser 238:91-100

Fishelson L, Popper D, Gunderman N (1971) Diurnal cyclic behavior of Pempheris oualensis Cuv. \& Val. (Pempheridae: Teleostei). J Nat Hist 5:503-506

Flagg CN, Smith SL (1989) On the use of the Acoustic Doppler Current Profiler to measure zooplankton abundance. Deep-Sea Res 36:455-474

Forrester GE (1991) Social rank, individual size and group composition as determinants of food consumption by humbug damselfish, Dascyllus aruanus. Anim Behav 42: 701-711

Fricke HW (1980) Control of different mating systems in a coral reef fish by one environmental factor. Anim Behav 28:561-569

Giske J, Aksnes DL, Fiksen O (1994) Visual predators, environmental variables and zooplankton mortality risk. Vie Milieu 44:1-9

Gladfelter WB (1979) Twilight migrations and foraging activities of the copper sweeper Pempheris schomburgki (Teleostei: Pempheridae). Mar Biol 50:109-119

Gliwicz MZ (1986) Predation and the evolution of vertical migration in zooplankton. Nature 320:746-748

Hamner WM, Jones MS, Carleton JH, Hauri IR, Williams DM (1988) Zooplankton, planktivorous fish, and water currents on a windward reef face: Great Barrier Reef, Australia. Bull Mar Sci 42:459-479

Harrison PL, Wallace CC (1990) Reproduction, dispersal and recruitment of Scleractinian corals. In: Dubinsky Z (ed) Ecosystems of the world, Vol 25. Coral reefs. Elsevier, Amsterdam, p 133-207

Harvey E, Shortis M (1995) A system for stereo-video measurement of sub-tidal organisms. Mar Technol Soc J 29: $10-22$

Harvey E, Fletcher D, Shortis MR, Kendrick GA (2004) A comparison of underwater visual distance estimates made by scuba divers and a stereo-video system: implications for underwater visual census of reef fish abundance. Mar Freshw Res 55:573-580

Hixon MA (1991) Predation as a process structuring coral reef communities. In: Sale FP (ed) The ecology of fishes on coral reefs. Academic Press, San Diego, CA, p 475-508

Hobson ES (1972) Activity of Hawaiian reef fishes during the evening and during transition between daylight and darkness. Fish Bull (Wash DC) 70:715-740

Hobson ES (1991) Trophic relations among fishes and zooplankton. In: Sale FP (ed) The ecology of fishes on coral reefs. Academic Press, San Diego, CA, p 69-93

Hobson ES, Chess JR (1978) Trophic relationships among fishes and plankton in the lagoon at Enewetak Atoll, Marshall Islands. Fish Bull (Wash DC) 1:133-153

Holzman R, Genin A (2003) Zooplanktivory by a nocturnal coral-reef fish: effects of light, flow, and prey density. Limnol Oceanogr 48:1367-1375

Holzman R, Reidenbach MA, Monismith SG, Koseff JR, Genin A (2005) Near-bottom depletion of zooplankton over a coral reef. II. Relationships with zooplankton swimming ability. Coral Reefs 24:87-94

Hovel KA, Morgan SG (1997) Planktivory as a selective force for reproductive synchrony and larval migration. Mar Ecol Prog Ser 157:79-95 
Jaffe JS, Ohman MD, De Robertis A (1998) OASIS in the sea: measurement of the acoustic reflectivity of zooplankton with concurrent optical imaging. Deep-Sea Res II 45: 1239-1253

Jobling M (1993) Bioenergetics: feed intake and energy partitioning. In: Rankin JC, Jensen FB (eds) Fish ecophysiology. Chapman \& Hall, London, p 1-44

Khalaf MA, Kochzius M (2002) Community structure and biogeography of shore fishes in the Gulf of Aqaba, Red Sea. Helgol Mar Res 55:252-284

Kingsford MJ, MacDiarmid AB (1988) Interrelations between planktivorous reef fish and zooplankton in temperate waters. Mar Ecol Prog Ser 48:103-117

Marnane MJ (2000) Site fidelity and homing behavior in coral reef cardinalfishes. J Fish Biol 57:1590-1600

Marnane MJ, Bellwood DR (2002) Diet and nocturnal forging in cardinalfishes (Apogonidae) at One Tree Reef, Great Barrier Reef, Australia. Mar Ecol Prog Ser 231:261-268

McFarland W, Wahl WC, Suchanek T, McAlary F (1999) The behavior of animals around twilight with emphasis on coral reef communities. In: Archer SN (ed) Adaptive mechanisms in the ecology of vision. Kluwer, Amsterdam, p 583-628

Morgan SG, Christy JH (1995) Adaptive significance of the timing of larval release by crabs. Am Nat 145:457-479

Mueller RP, Brown RS, Hop H, Moulton L (2006) Video and acoustic camera techniques for studying fish under ice: a review and comparison. Rev Fish Biol Fish 16:213-226

O'Brien WJ (1987) Planktivory by freshwater fish: thrust and parry in the pelagia. In: Kerfoot WC, Sih A (eds) Predation direct and indirect impacts on aquatic communities. University Press of New England, Hanover, p 3-16

Editorial responsibility: Jon Hare (Contributing Editor), Narragansett, Rhode Island, USA
Pearre S (2003) Eat and run? The hunger/satiation hypothesis in vertical migration: history, evidence and consequences. Biol Rev 78:1-79

Platell ME, Potter IC (1999) Partitioning of habitat and prey by abundant and similar-sized species of the Triglidae and Pempherididae (Teleostei) in coastal waters. Estuar Coast Shelf Sci 48:235-252

Randall JE (1983) Red Sea reef fishes. IMMEL, London

Rilov G, Benayahu Y (2000) Fish assemblage on natural versus vertical artificial reefs: the rehabilitation perspective. Mar Biol 136:931-942

Sale PF (1997) Visual census of fishes: How well do we see what is there? In: Lessios HA, MacIntyre IG (eds) Proceedings of the 8th International Coral Reef Symposium, Vol 2. Smithsonian Tropical Research Institute, Balboa, p 1435-1440

Sommer U, Berninger UG, Bottger-Schnack R, Cornils A and 8 others (2002) Grazing during early spring in the Gulf of Aqaba and the northern Red Sea. Mar Ecol Prog Ser 239: 251-261

Wiebe PH, Benfield MC (2003) From the Hensen net toward four-dimensional biological oceanography. Prog Oceanogr 56:7-136

Yahel R, Yahel G, Genin A (2002) Daily cycles of suspended sand at coral reefs: a biological control. Limnol Oceanogr 47:1071-1083

Yahel R, Yahel G, Berman T, Jaffe JS, Genin A (2005a) Diel pattern with abrupt crepuscular changes of zooplankton over a coral reef. Limnol Oceanogr 50:930-944

Yahel R, Yahel G, Genin A (2005b) Near-bottom depletion of zooplankton over coral reefs. I. Diurnal dynamics and size distribution. Coral Reefs 24:75-85

Submitted: July 31, 2006; Accepted: February 23, 2007

Proofs received from author(s): June 27, 2007 